\title{
The Drosophila rhomboid gene mediates the localized formation of wing veins and interacts genetically with components of the EGF-R signaling pathway
}

\author{
Mark A. Sturtevant, ${ }^{1}$ Margaret Roark, ${ }^{1,2}$ and Ethan Bier ${ }^{1}$ \\ ${ }^{1}$ Department of Biology and Center for Molecular Genetics, University of California, San Diego, California USA; \\ ${ }^{2}$ Department of Biology, California State University, San Marcos, California 92096 USA
}

\begin{abstract}
The rhomboid (rho) gene, which encodes a transmembrane protein, is a member of a small group of genes (ventrolateral genes) required for the differentiation of ventral epidermis in the Drosophila embryo. The ventrolateral genes include spitz, which encodes an EGF-like ligand, and Star. The receptor for spitz may be the gene encoding the Drosophila epidermal growth factor-receptor $(E g f-r)$ because the phenotype resulting from partial loss of function of Egf-r is similar to that of ventrolateral group mutants. Among ventrolateral genes encoding cell-surface or secreted proteins, rho is the only member expressed in a localized pattern corresponding to cells requiring the activity of the ventrolateral pathw-y. In this paper we provide evidence that spatial localization of rho plays an analogous role in establishing vein pattern in the adult wing. rho is expressed in early wing disc cells likely to be wing vein primordia and later is sharply restricted to developing veins. Flies homozygous for the viable rhove allele have missing veins and rho fails to be expressed in rhove mutant wing discs. Ectopic expression of rho during wing development leads to the formation of extra veins. Gene dosage studies among ventrolateral genes suggest that the rho product (Rho) may facilitate Spi-EGF-R signaling, resulting in activation of RAS. We discuss models for how localized expression of Rho may amplify signaling mediated by ubiquitously distributed ligand and receptor components.
\end{abstract}

[Key Words: rhomboid; Drosophila; wing veins; imaginal disc development; tyrosine kinase signaling; EGF-R]

Received January 19, 1993; revised version accepted April 6, 1993.

The rhomboid gene $(r h o)$ is required early for differentiation of ventral epidermis in response to the dorsal morphogen gradient in the Drosophila embryo. In the absence of $r$ ho function, longitudinal strips of ventrolateral cells in the early blastoderm embryo that would ordinarily give rise to ventral epidermis of the larva fail to differentiate (Jürgens et al. 1984; Mayer and Nüsslein-Volhard 1988). As a consequence of this early defect, rho mutant larvae lack portions of ventral epidermis. The rho gene is also required at other times during embryogenesis in a variety of capacities. For example, rho is necessary for the proper development of cells along the ventral midline, for the formation of two stretch receptor organs in each abdominal hemisegment, and for the formation of the first row of denticles in each segment (Mayer and Nüsslein-Volhard 1988; Bier et al. 1990). In addition to these embryonic phenotypes, flies homozygous for the adult viable allele $r h o^{\text {ve }}$ lack distal portions of wing veins (Lindsley and Grell 1968; Diaz-Benjumea and García-Bellido 1990a; Lindsley and Zimm 1992).

The rho gene is expressed in a complex dynamic pattern during embryogenesis that correlates well with the location of cells requiring rho activity (Bier et al. 1990). Thus, rho is sequentially expressed in ventrolateral strips of cells, in cells along the ventral midline, in stretch receptor precursor cells, and then in rows of cells at the segment boundary. The tight correspondence between expression pattern and function suggests that rho is required for the proper development of cells expressing rho. From DNA sequence analysis, the rho gene is predicted to encode a novel integral membrane protein (rho) that spans the membrane between three and seven times (Bier et al. 1990). These data are consistent with rho acting as part of a receptor mechanism or, alternatively, acting to modulate differential adhesive properties between neighboring cells required for intercellular communication or morphogenesis.

Embryos lacking the function of two other known genes [spitz (spi) and Star (S)] exhibit phenotypes that are nearly identical to those of rho mutants (Mayer and Nüsslein-Volhard 1988; Bier et al. 1990; Klämbt et al. 1991). Another mutant [pointed (pnt)] has a similar dorsoventral phenotype to rho, spitz, and Star but differs in other aspects, such as midline defects (Mayer and Nüsslein- 
Volhard 1988; Klämbt 1993). Sequence data suggest that the spi gene encodes a growth factor-type molecule (Spi) of the epidermal growth factor/transformation growth factor- $\alpha$ (EGF/TGF- $\alpha$ ) class that may be either membrane bound or secreted (Rutledge et al. 1992). The $S$ gene has also been cloned (A. Kolodkin, U. Banerjee, and C.S. Goodman, pers. comm.) and is predicted from conceptual translation to encode a single pass (type II) transmembrane protein. Because mutations in this group of genes, known as the spitz-group or ventrolateral group, result in strikingly similar developmental defects, it is likely that they function in a common developmental pathway. This ventrolateral pathway may also involve the gene $(E g f-r)$ encoding the Drosophila EGF-receptor (EGF-R). A role for EGF-R in ventrolateral signaling is supported by the following evidence: (1) Embryos homozygous for a weak embryonic lethal allele of Egf-r exhibit a phenotype very similar to that of ventrolateral group mutants, including a loss of two lateral stretch receptor organs (Clifford and Schüpbach 1992; Raz and Shilo 1992); (2) spi encodes an EGF/TGF- $\alpha$-like growth factor (Rutledge et al. 1992); and (3) defects in tissues

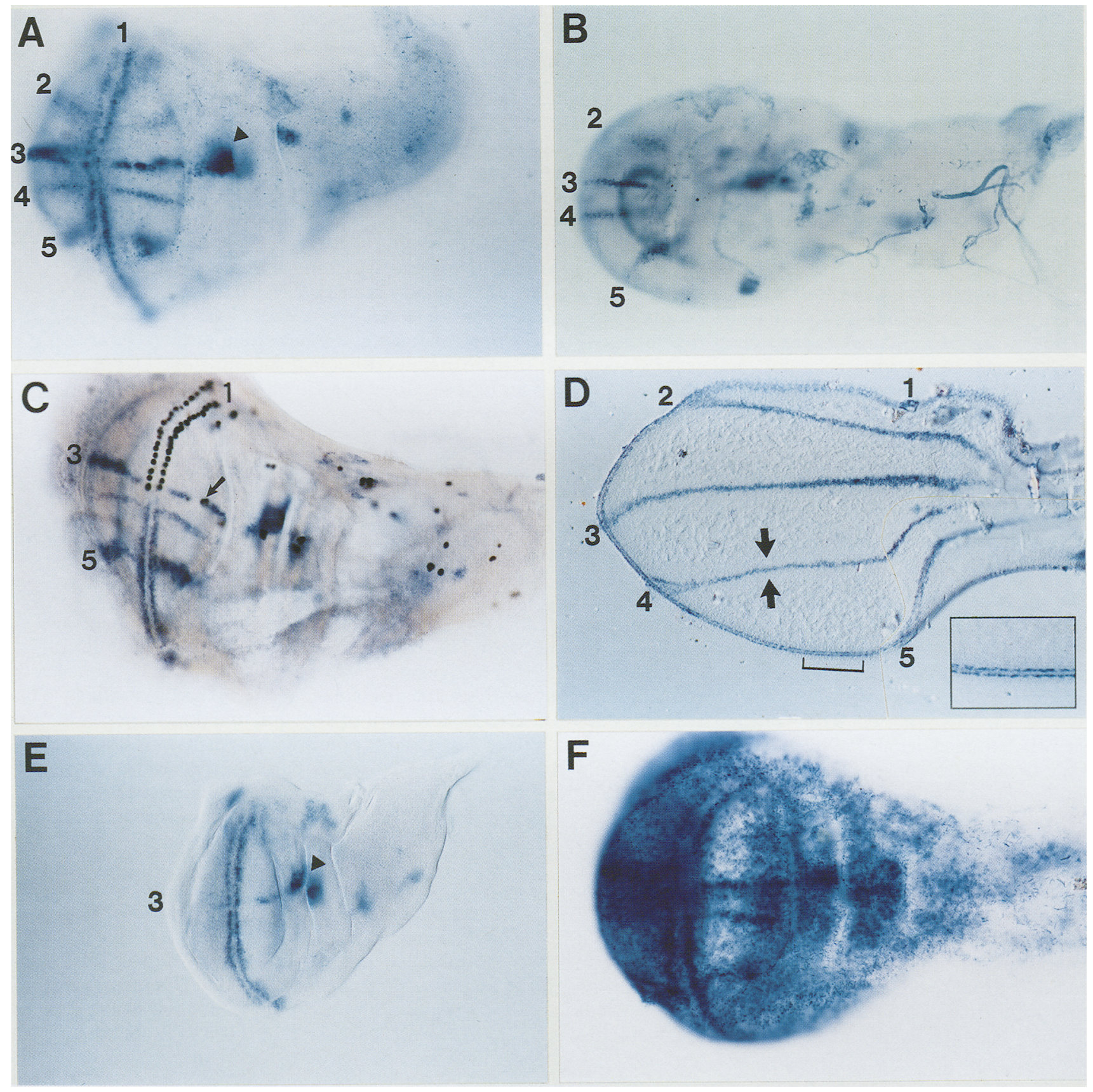

Figure 1. (See facing page for legend.) 
derived from ventrolateral positions in the blastoderm resulting from $r h o, s p i, S$, and pnt mutations are primarily restricted to epidermal derivatives (Mayer and Nüsslein-Volhard 1988; Bier et al. 1990). These observations suggest a model in which the product of the rho gene is required for some aspect of signaling between Spi and EGF-R. Because both the putative ligand (Spi) and receptor (EGF-R) are expressed ubiquitously in the embryo and in imaginal discs (Kammermeyer and Wadsworth 1990; Zak et al. 1990; Katzen et al. 1991; Rutledge et al. 1992; Zak and Shilo 1992; M. Sturtevant, in prep.), it is likely that localized $r$ ho expression is important for restricting the spatial and temporal activity of the ventrolateral pathway.

In this paper we show that localized rho expression in wing vein primordia directs these cells to differentiate as veins. rho expression is largely eliminated in $r h o^{\text {ve }}$ wing discs correlating with the absence of veins in adult wings. Conversely, ectopic rho expression causes extra vein formation. We also report dosage-sensitive interactions between rho, spi, Egf-r, and components of the RAS system, which suggest that they operate in a common signal transduction pathway. Finally, we outline models for how local activity of the rho protein might amplify or facilitate interaction between Spi and EGF-R, which are ubiquitously expressed.

\section{Results}

rho is expressed in wing vein primordia during wing disc development

As a first step in analyzing tho function during wing development, we determined the pattern of rho expression by tissue in situ hybridization to wild-type wing discs with a digoxigenin-labeled rho RNA probe. rho expression in pouch-stage discs from wild-type wandering third-instar larvae and early prepupae consists of a pattern of intersecting stripes (Fig. 1A), as well as a patch of cells likely to give rise to wing hinge veins /arrowhead in Fig. 1A; see also fate map in Campuzano and Modolell 1992). The position of the strong transverse band of rhoexpressing cells corresponds well with the known location of cells that will become the margin of the wing, including vein $\mathrm{Ll}$ along the anterior margin. These marginal cells can be resolved as two closely spaced parallel rows of $r$ ho-expressing cells separated by a small gap of nonexpressing cells. The four stripes of rho expression that cross the future margin extend into separate primordia for the dorsal wing surface (which lies proximal to the future margin) and the ventral surface (cells distal to the future margin). Although there are no known definitive markers for all wing vein primordia at this early developmental stage, a pattern of evenly spaced stripes crossing the future wing margin is what would be expected from the fate map of the uneverted disc (Campuzano and Modolell 1992). A similar pattern of rho expression is observed slightly later when the disc has begun to evert $\sim 5 \mathrm{hr}$ after pupariation (AP) (Fig. 1B). By this stage the longitudinal stripes of rho expression intersecting the margin have been brought into register on both the dorsal and ventral surfaces of the disc. Because we suspected that the transverse stripes in third-instar discs correspond to the primordia for the four longitudinal wing veins (L2-L5), we performed double-labeling experiments with known wing vein markers. Although rho is the earliest known gene to be expressed in all presumptive longitudinal wing veins, the A101 P-lacZ enhancer trap in the neuralized gene marks sensory mother cells along the margin and vein L3 starting in third-instar discs (Bellen et al. 1989). In addition, an antibody to the product of the hairy gene labels the wing margin and wing vein L2 and L3 at a later stage during early pupariation (Carrol and Whyte 1989). We visualized the ex-

Figure 1. rho expression in wild-type and mutant discs. $(A)$ rho transcripts detected by whole-mount tissue in situ hybridization in an uneverted pouch stage late third-instar disc. The pouch is the oval domain of cells surrounded by multiple infoldings, which gives rise to adult wing structures. The presumptive veins are numbered from anterior to posterior, the margin giving rise to vein $\mathrm{Ll}$ (see legend to Fig. 2). Wing pouch cells proximal to the future margin comprise the anlagen for the dorsal surface of the wing, and those distal to the margin give rise to the ventral wing surface. rho is also expressed in a small patch of cells that form part of the base of the wing (arrowhead). $(B)$ rho expression 5-6 hr postpupariation, when the wing pouch has begun to evert, bringing the two future surfaces of the wing into close proximity. (C) Double label of $r$ ho RNA (blue-purple alkaline phosphatase reaction product) and $\beta$-galactosidase protein (brown peroxidase reaction product) derived from the Al01 enhancer trap insertion in the neuralized gene. A101 is expressed in all sensory mother cells in the wing (Bellen et al. 1989) including precursors for sensilla lining the future wing margin (double row of dark cells) and precursors of companiform sensilla that lie on the third wing vein (arrow). (D) rho in wings 30 hr postpupariation. Expression in cross veins is observed in older wings. Note a strip of densely packed cells about 4-5 cell diameters wide flanking both sides of each row of rho-expressing cells can be distinguished morphologically from cells in central portions of intervein domains by Nomarski optics (arrows). (Inset) High magnification of wing margin marked with bracket showing that both surfaces of the wing vein express rho (arrows). (E) rho expression in a pouch stage $r h o^{v e} / r h o^{v e}$ wing disc. Note that staining in the patch of cells at the base of the wing (arrowhead) is split into two staggered groups of cells instead of forming a single compact patch as in wild type (cf. $A$ ). ( $F$ ) rho expression in discs homozygous for a rho ${ }^{\text {stg } H S}$ insertion. Expression along vein primordia can be resolved above the strong general background. The degree of $r$ ho overproduction shown here is typical for this transformant line; however, a few discs had less general staining. Non-heat-shock wing vein phenotypes from this line also vary to some degree. Ubiquitous rho expression was also seen in other imaginal discs as well as in the larval CNS of this transformant line. The loss of staining in $r$ hove discs and ubiquitous tho expression in HS-rho discs is not the result of variation in background staining as wild-type embryos included in the same hybridization chamber showed the normal sharp pattern of $r$ ho expression without background. Furthermore, $r h o^{v e}$, rho $o^{S t g} H$, and wild-type discs were all processed in parallel in adjacent hybridization chambers, and each stained consistently in its distinctive pattern. 
pression of lacZ from the A101 enhancer trap (Fig. 1C) with antibodies followed by peroxidase reactions (brown staining) and rho RNA by whole-mount in situ hybridization followed by an alkaline phosphatase reaction (blue staining). The coincidence of A101 and rho staining along the presumptive margin and vein L3 (arrow) supports the view that $r$ ho is expressed in register with wing vein primordia. rho expression is also coincident with Hairy along presumptive veins (not shown).

Additional evidence that rho is expressed in cells forming wing veins was obtained by examining expression at later stages of wing development when the pupal cuticle separates from the underlying tissue permitting access to histological reagents. In these older developing wings (25-35 hr AP), rho transcripts are sharply restricted to veins (Fig. 1D). rho is expressed in vein cells on both the dorsal and ventral surfaces of the wing, as can be seen in preparations in which the surfaces of the wing have separated slightly during mounting (Fig. 1D, inset). At this stage, a strip of cells adjacent to rho-expressing cells (between two arrows, Fig. 1D) can be distinguished morphologically from the more loosely packed cells in central portions of intervein domains. As much of the extra wing vein material formed in wings of flies ubiquitously expressing rho is the result of thickening of pre-existing veins (see below and Fig. 2E,F), this strip of densely packed cells may be most susceptible to ectopic rho activity. We conclude that $r$ ho is likely to be the earliest known gene to be expressed in longitudinal wing vein primordia and that rho continues to be expressed in developing wing veins during the partitioning of the wing into vein versus intervein territories.

It should be noted that spi and Egf-r are expressed ubiquitously in wing discs [spi expression (M. Sturtevant, unpubl.); Egf-r expression (Kammermeyer and Wadsworth 1990; Katzen et al. 1991; Zak and Shilo 1992; M. Sturtevant, unpubl.)]. Thus, in wing discs, as in the embryo, rho is expressed in a strictly localized pattern, whereas other members of the signaling pathway such as the ligand $(s p i)$ and receptor $(E g f-r)$ are more generally distributed.

\section{rho expression in wing vein primordia is required for adult vein formation}

The homozygous viable wing vein mutation ve has been determined to be allelic to rho (Diaz-Benjumea and García-Bellido 1990a; E. Bier, unpubl.). As loss-of-function rho alleles are embryonic lethal, one possibility is that the viable $r$ hove allele is a rho promoter mutation. This possibility is consistent with genetic transfection data (E. Bier, unpubl.) and with the existence of a polymorphism in the rho promoter region in $r h o^{v e}$ genomic DNA, which from Southern blot analysis appears to be a 600-bp to 800-bp deletion (M. Roark, unpubl.). To test this interpretation of the $r o^{v e}$ mutation, we hybridized a rho probe to discs obtained from larvae homozygous for $r h o^{v e}$. $r h o^{v e} / r h o^{v e}$ flies lack distal segments of wing veins, especially veins L4 and L5 (see Fig. 2B, below). At the early pouch stage (Fig. 1E) and during early disc eversion, rho is expressed in the normal pattern along the future margin but is absent from the presumptive longitudinal wing veins, except for weak expression in part of the third vein primordium. Lack of rho staining in presumptive wing vein cells is not an artifact of poor staining reactions, as expression is normal in other imaginal discs isolated from $r h o^{v e}$ larvae and in other parts of the wing disc, although a patch of staining in the presumptive wing hinge region is shifted relative to wild type (Fig. 1E, arrowhead). By $30 \mathrm{hr} \mathrm{AP,} \mathrm{rho} \mathrm{expression} \mathrm{in} \mathrm{the}$ developing wing forecasts the defects in $r$ hove wings /not shown). The loss of veins can also be observed at this stage with a probe to the Delta gene, which is normally restricted to vein cells at this time (M. Sturtevant and E. Bier, in prep.).

\section{Localized rho expression is required for restricted wing vein formation}

To test our hypothesis that localized rho expression dictates cell fate choices, we placed a full-length rho cDNA clone under the control of a heat-inducible promoter in the hs-CaSpeR P-element transformation vector (see Materials and methods). When transformant lines were heat-shocked during late larval and early pupal stages, we recovered adults with a range of abnormal wing phenotypes and roughened eyes. The most weakly affected wings had slight deltas at the junction of longitudinal veins with the margin. Moderately affected wings had more pronounced deltas and, often, the rudiments of ectopic veins. Strongly affected wings had thickened or fused longitudinal veins, extensive ectopic veins, and often had large blisters where the two wing surfaces separated in a bubble. The ectopic veins can be identified as such by a variety of criteria, including dark pigmentation, thickened and raised cuticle, and increased density of bristles (two- to threefold). The presence of extra vein material is evident during pupal development when excess vein precursor structures known as lacunae can be observed by Nomarski optics and by the expression of several pupal-stage markers for wing veins $(M$. Sturtevant and $\mathrm{E}$. Bier, in prep.).

Without heat induction, the transformant lines described above have either wild-type wings or exhibit only minor wing vein deltas (Fig. 2, cf. A and C). Several other transformant lines have more severe wing vein defects in the absence of heat induction (Fig. 2D-F). The constitutive wing vein phenotypes of different transformant lines can be ordered in a progression paralleling the phenotypic series resulting from heat-shocking transformant lines with weak constitutive phenotypes. Presumably, constitutive phenotypes are the result of various degrees of leaky or enhancer-driven expression of the heat shock promoter in wing primordia. For the sake of simplification, we have classified the various transformant lines as weak $\left(r h o^{W k} H S\right)$, moderate $\left(r h o^{M o d} H S\right)$, or strong (rho ${ }^{\text {Stg } H S}$ ) based on the severity of the constitutive wing vein phenotype.

As expected, rho expression was elevated throughout 
A

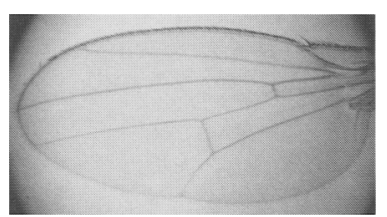

wild type

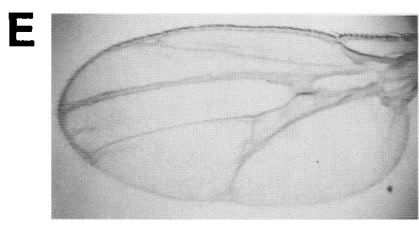

Stg $\mathrm{HS} /+$
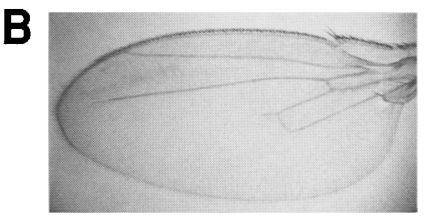

$\mathrm{ve} / \mathrm{ve}$

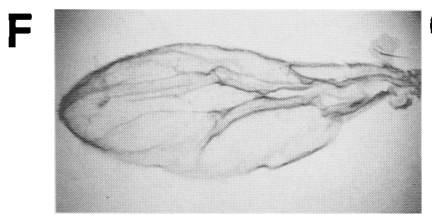

Stg HS/Stg HS
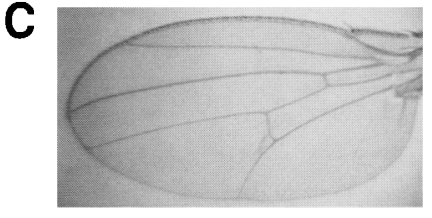

Wk HS/+
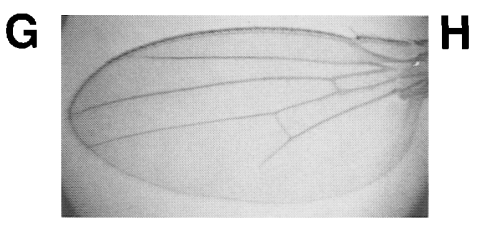

Wk HS/+ ve/ve

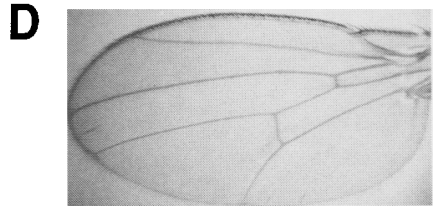

Mod HS/+

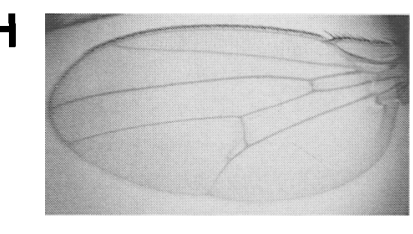

Mod HS/+ ve/+

Figure 2. Wing vein phenotypes resulting from insufficient rho function and from excess rho activity. (A) A wild-type wing. The major wing veins are the marginal vein $(\mathrm{L} 1)$; the longitudinal veins (L2-L4, numbered from anterior to posterior); and two cross veins (the anterior cross vein connects vein $\mathrm{L} 3$ to vein $\mathrm{L} 4$; the posterior cross vein connects vein $\mathrm{L} 4$ to vein $\mathrm{L} 5$ ). The marginal L1 vein ends where it intersects L3, although a subset of sensory bristles that line the margin extend further, ending between L3 and L4. (B) A typical $r h o^{v e} / r h o^{v e}$ wing. Longitudinal veins L3-L4 are shortened and do not reach the margin. Veins L4 and L5 are the most affected. L2 is often normal in our $r h o^{v e}$ stock (as shown here), but in some individuals it is drawn back a short distance from the margin. Cross veins are not affected. (C) A rho $\mathrm{Hk}_{\mathrm{HS}} /+$ wing. Small deltas form at the junction of L3 and L4 with the margin, and an ectopic spur perpendicular to the posterior cross vein is often observed. $(D)$ A rho $\mathrm{rod} \mathrm{HS}_{\mathrm{H}}+$ wing. Prominent deltas form at the junction of $\mathrm{L} 3$ and $\mathrm{L} 4$, and a rudiment of an extra vein $(\mathrm{r} 3,4)$ is frequently observed equally spaced between L3 and L4. $(E)$ A rho $o^{\text {stg } H S} /+\mathrm{wing}$. L3 and L4 deltas are greatly enlarged, becoming continuous along the margin with $\mathrm{r} 3,4$. Longitudinal veins are thickened (especially L3), and extra longitudinal vein material lies between the margin and L2. Blisters often form centered around the anterior cross vein, causing separation of the dorsal and ventral surfaces. $(F) \mathrm{A} \mathrm{rho} \mathrm{S}^{\text {Stg } H S} / \mathrm{rho} \mathrm{O}^{\text {Stg } H S}$ wing. Longitudinal veins are greatly broadened and often fuse into large continuous vein surfaces. Large blisters occupying most of the wing surface are also common. (G) A rho $o^{W k} H S /+r h o^{v e} / r h o^{v e}$ wing. Heterozygous $r h o^{\text {Wk } H S}$ (which has little phenotype on its own) significantly suppresses the rho ${ }^{\text {ve }} /$ rho $^{\text {ve }}$ loss-of-vein phenotype. Veins $\mathrm{L} 3$ and L4 are complete, and L5 is longer than in $r h o^{v e} / r_{h o}{ }^{v e}$. $(H) \mathrm{A} r h o^{M o d} \mathrm{HS} /+r h o^{v e} /+$ wing. Heterozygous rho ${ }^{v e}$ (which alone has no phenotype) significantly suppresses the rho ${ }^{\text {Mod } H S}$ excess vein phenotype. Deltas at the junction of L3 and L4 with the margin are reduced, and the extra vein rudiment between L3 and L4 rarely forms.

discs derived both from HS-rho transformant lines that were heat-shocked (not shown) and from a non-heatshocked transformant line with a strong constitutive wing vein phenotype (Fig. 1F). The formation of extra veins is observable by $30 \mathrm{hr} A \mathrm{~A}$ in $r h o^{\text {stg } H S}$ wings because extra lacunae marked by cells expressing rho can be observed above the general background. Extra vein precursor cells also express the Delta gene at this stage (M. Sturtevant and E. Bier, in prep.). The correlation between $r$ ho expression in $r h o^{v e} / r h o^{v e}$ and in HS-rho discs with the corresponding loss and gain of wing vein phenotypes suggests that $r$ ho is required for proper vein formation and that localized expression of rho along vein primordia is important in limiting the number of cells differentiating as vein tissue.

\section{Dosage-sensitive interactions between ho $^{\text {ve }}$ and HS-rho}

The reciprocal effects of $r h o^{v e} / r h o^{v e}$ and HS-rho alleles on rho expression in discs and the fact that these mutations have opposite phenotypes is consistent with rho function being reduced in $r h o^{v e} / r h o^{v e}$ and increased in HS-rho insertions. To test this idea further, we asked whether there are dosage-sensitive interactions between $r h o^{v e}$ and HS-rho insertions. Although one copy of a $r h o^{W k} H S$ insertion causes only a very weak constitutive excess vein phenotype (Fig. $2 \mathrm{C}$ ), heterozygous $\mathrm{rho}^{\text {Wk } H S}$ strongly suppresses the $r$ ho ${ }^{v e} /$ rho $^{\text {ve }}$ phenotype (Fig. 2G). The interaction between $r o^{v e}$ and HS-rho works both ways as there is also considerable dominant suppression of the rho Mod HS phenotype by heterozygous $r$ hove (Fig. $2 \mathrm{H})$. We note that $r h o^{v e}$ is a purely recessive mutation in a wild-type background. These reciprocal interactions support the view that $r h^{v e}$ is a partial loss-of-function allele and that $r h o^{H S}$ insertions act as dominant gain-offunction alleles.

\section{Genetic interactions between rho and other ventrolateral group mutations}

To determine whether there are dosage-sensitive interactions between rho and other ventrolateral group genes, we combined the $r$ hove allele and several HS-rho inserts of differing constitutive strengths with alleles of Egf-r and other ventrolateral group genes. The results of these crosses are summarized in Table 1, and examples of enhanced or suppressed rhove or HS-rho phenotypes are shown in Figure 3. All interactions observed are consistent with models in which rho acts synergistically with EGF-R signaling components.

Flies homozygous for the partial loss-of-function 
torpedo allele of Egf-r $\left(E g f-r^{\text {top }}\right)$ usually have wild-type wings but occasionally lack vein segments, whereas individuals transheterozygous for Egf- $r^{\text {top }}$ and an Egf-r deficiency (DfEgf-r) always lack a large section of vein $L 4$ (Fig. 3A). Mosaic analysis of stronger Egf-r alleles has shown that EGF-R function is required for the formation of all wing veins (Diaz-Benjumea and García-Bellido 1990b). The dominant gain-of-function Ellipse allele $\left\langle E g f-r^{E l p}\right\rangle$ alone has a very weak wing phenotype when heterozygous (Baker and Rubin 1989, 1992), but generates deltas and sporadic spurs along other veins in some individuals when homozygous (Fig. 3B). Interaction of rho and Egf-r mutations is revealed in several combinations of alleles. Homozygous Egf-r $r^{\text {top }}$ or heterozygous DfEgf-r enhances the $r h o^{v e} / r h o^{v e}$ loss-of-function phenotype (Fig. 3C, cf. Fig. 2B), and flies of the genotype Egf$r^{\text {top}} / \mathrm{DfEgf}-r_{;} r r_{0} o^{\text {ve }} / r h o^{v e}$ lack virtually all wing veins (Fig. 3E). This latter phenotype is much more severe than the sum of vein deletions observed in Egf-rop $/ \mathrm{Df} E g f-r$ and $r h o^{v e} / r h o^{v e}$ separately. If the phenotypes were only additive, the double mutant combination would resemble the $r h o^{v e} / r h o^{v e}$ phenotype. Reciprocally, Egf-r ${ }^{\text {Elp }}$ suppresses the $r h o^{v e} / r h o^{v e}$ phenotype significantly when heterozygous and nearly completely when homozygous (Fig. 3D). There is also enhancement of $r h O^{W k} H S$, rho ${ }^{\text {Mod HS }}$, and $r h O^{\text {Stg HS }}$ extra wing vein phenotypes by $E g f-r^{E I_{p}} /+($ Table 1; Fig. 3F, cf. Fig. 2D) and suppression of the $r h 0^{\text {Mod } H S}$ wing phenotype by homozygous Egf-rtop or DfEgf-r/ + . The rho ${ }^{\text {Stg } H S}$ phenotype, however, is not dramatically suppressed by either homozygous Egf-r ${ }^{\text {top }}$ or Egf-rop $/ \mathrm{DfEgf-r}$. This may be the result of Egf-rtop being a relatively mild Egf-r allele in the wing or, alternatively, of rho activating other signaling pathways in addition to the EGF-R pathway.

We also analyzed interactions between HS-rho and mutations in genes involved in regulating RAS activity known to act downstream of tyrosine kinases in the eye (Fortini et al. 1992). Consistent with a model in which rho amplifies EGF-R signaling, rho ${ }^{M o d} H S$ and $r h o^{S t g} H S$ phenotypes are strongly suppressed by a heterozygous recessive Ras1 allele and HS-rho constructs enhance the rough eye phenotype of activated Ras $1^{\text {Val12 }}$ expressed under the control of the sevenless (sev) promoter (Table 1). All HS-rho insertions tested also interact with Gap1 mutations. The Gap1 product antagonizes EGF-R activation of RAS during eye development, presumably by increasing the endogenous GTPase activity of RAS /Gaul et al. 1992). In the wing, Gap1 mutations also appear to antagonize RAS activation as semilethal alleles of the Gap1 gene act as dominant enhancers of HS-rho phenotypes (Table 1; Fig. 3H, cf. Fig. 2D). A role for Gap1 in vein formation is also revealed by escaper Gap1/Gap1 or Gap1/DfGap1 flies, which have ectopic veins typical of rho ${ }^{M o d ~ H S}$ phenotypes (Fig. 3G; see also Fig. 1M in Gaul et al. 1992). No dominant interactions were observed between HS-rho insertions and sos [sos encodes a nucle-

Table 1. Genetic interactions between loss- and gain-of-function tho alleles and other mutations affecting components of the EGF-R signaling pathway

\begin{tabular}{|c|c|c|c|c|}
\hline \multirow[b]{2}{*}{ Test genotype } & \multicolumn{4}{|c|}{ rho genotype (phenotype scored) ${ }^{a}$} \\
\hline & $r h o^{v e} / r h o^{v e}$ & rhowk $H S /+$ & rho $o^{\text {Mod HS}} /+$ & $r h o^{S t g H S} /+$ \\
\hline$E g f-r^{E l p} /+$ & -- (L3 to margin) & $++(\uparrow \Delta 3,4)$ & $\begin{array}{c}++(\uparrow \Delta 3,4 \text { and } \\
\text { thick } L 3 / L 4)\end{array}$ & $+\quad$ (blisters in males) \\
\hline$E g f-r^{E l p} / E g f-r^{E l p}$ & $\begin{array}{l}--(\mathrm{L} 3 \text { and } \mathrm{L4} \\
\text { to margin) }\end{array}$ & ND & ND & ND \\
\hline Egf-r $r^{t o p} / E g f-r^{t o p}$ & $\begin{array}{l}++ \text { (L5 prox. to } \\
\text { post. X-vein) }\end{array}$ & ND & $--($ no $\Delta 3,4)$ & $0 /-$ \\
\hline DfEgf-r/+ & $\begin{array}{l}++ \text { (L5 prox. to } \\
\text { post. X-vein })\end{array}$ & $--\mid$ no $\Delta 3,4)$ & $--(\downarrow \Delta 3,4)$ & $0 /-$ \\
\hline DfEgf-r/Egf-rtop & $\begin{array}{c}++\quad(\mathrm{L} 2-\mathrm{L} 5 \\
\text { retracted })\end{array}$ & ND & ND & $\begin{array}{c}\text { - } \\
\text { (no blisters in } \\
\text { females })\end{array}$ \\
\hline$S /+$ & $\begin{array}{l}++ \text { (L5 prox. to } \\
\text { post. X-vein) }\end{array}$ & $--($ no $\Delta 3,4)$ & $--($ no $\Delta 3,4)$ & $\begin{array}{r}- \text { (no blisters or } \\
\text { thick veins })\end{array}$ \\
\hline spi/t+ & $+\quad(\mathrm{L} 2$ retracted $)$ & $--($ no $\Delta 3,4)$ & $-\quad(\downarrow \Delta 3,4)$ & 0 \\
\hline Sppil++ & $\begin{array}{c}++\mathrm{L} 2 \text { and } \mathrm{L} 5 \\
\text { retracted })\end{array}$ & ND & ND & ND \\
\hline Ras1/+ & ND & ND & $--($ reduced $\Delta 3,4)$ & -- (no blisters $)$ \\
\hline $\mathrm{p}\left[\operatorname{sev} \operatorname{Ras} 1^{\text {Val12}}\right] /+$ & ND & $++[\uparrow$ rough eye $]$ & $+\star$ [longer $\mathrm{r} 3,4]$ & $++[\uparrow$ rough eye $]$ \\
\hline Gap-1/+ & ND & $++(\uparrow \Delta 3,4)$ & $\begin{array}{c}++(\uparrow \Delta 3,4 \text { and } \\
\text { thick } \mathrm{L3} / \mathrm{L} 4)\end{array}$ & $+\quad$ (blisters in males) \\
\hline $\operatorname{sos} /+$ & ND & 0 & 0 & 0 \\
\hline$d r k /+$ & ND & 0 & 0 & 0 \\
\hline pnt/+ & 0 & 0 & 0 & 0 \\
\hline$f t /+$ & 0 & 0 & 0 & 0 \\
\hline$d s /+$ & 0 & 0 & 0 & 0 \\
\hline inf $/+$ & 0 & 0 & 0 & 0 \\
\hline $1(1)$ mys / + & 0 & 0 & 0 & 0 \\
\hline
\end{tabular}

(See facing page for footnote.) 
otide exchange factor (Rogge et al. 1991; Simon et al. 1991)] or $d r k$ [drk encodes the Drosophila homolog of GRB2/Sem5 (Clark et al. 1992; Lowenstein et al. 1992; G. Rubin, pers. comm.)].

We tested for interactions between rho and other ventrolateral group mutants in similar crosses to those described above. Among the ventrolateral genes, rho interacts most dramatically with $S$ in wing vein formation. Heterozygous $S$ enhances the $r h o^{v e} / r h o^{v e}$ loss-of-vein phenotype (Fig. 3I) and almost completely suppresses the rho ${ }^{\text {stg } H S}$ extra vein phenotype (Fig. 3J). A role for spi in vein formation is also likely because vein $\mathrm{L} 2$ is significantly shortened in spil +; rho ${ }^{v e} / \mathrm{rho}^{v e}$ flies and the $r h o^{v e} / r h o^{v e}$ phenotype is more enhanced by double heterozygous spi $S$ than by heterozygous $S$ alone (Table 1). In contrast to the strong interactions between rho and Egf-r alleles and between $r$ ho and $S$, we did not observe any interaction between HS-rho and pnt.

The interactions described above are quite specific. We have also examined interactions between HS-rho insertions and many other wing vein mutants and have found very few other interactions comparable with those de- scribed above (Table 1). For example, there are no obvious dominant interactions between HS-rho insertions and mutants in the integrin-encoding genes $1(1)$ myospheroid gene or inflated (Brower and Jaffee 1989; Wilcox et al. 1989; Zusman et al. 1990). Combinations of mutant alleles of these genes induce blisters and might be expected to interact nonspecifically with HS-rho insertions, yet they do not. Interestingly, the few strong genetic interactions that we have observed outside of those described above include genes encoding EGF-type repeats such as Notch, Delta, and Serrate (Table 1; M. Sturtevant and E. Bier, in prep.). As further evidence for the specificity of the above interactions, we are currently conducting a screen for dominant enhancers of $r$ hove/ $r h o^{v e}$ yielding phenotypes equivalent to that observed with DfEgf-r $r+$ of $S /+$ and have found only a small handful of loci acting as such strong enhancers.

\section{Discussion}

In the wing disc, as in the embryo, rho is expressed in a localized pattern. This localized expression in presump-

The recessive (homozygous) rho ${ }^{\text {ve }}$ mutation and HS-rho insertions (heterozygous) with weak (rho ${ }^{\text {Wk } H S}$ ), moderate (rho ${ }^{\text {Mod } H S}$ ), and strong $\left(r h o^{S t g} H S\right)$ dominant constitutive phenotypes were combined with mutations in other genes as indicated in the first column. A variety of rho phenotypes were scored for enhancement or suppression for each combined genotype to gauge genetic interactions. Genetic interactions depicted in Fig. 3 are highlighted in bold print. Phenotypes with high penetrance (in parentheses) were chosen to quantify each interaction.

Interactions were rated as follows: $(++)$ if $>90 \%$ of all wings examined showed an unambiguous enhancement relative to wild-type backgrounds (several of which have been tested for each rho genotype); $1+\mid$ if $>50 \%$ of wings were enhanced; $(--\mid$ if $>90 \%$ of wings were suppressed relative to wild-type backgrounds; $(-)$ if $>50 \%$ of wings were suppressed; (0) if no obvious suppression or enhancement was observed. In a few cases, apparent weak suppressive interactions (denoted by $0 /-$ ) were perceived as shifts in the average magnitude of a given phenotype but could not be unequivocally scored as such. At least 20 wings and typically $50-100$ wings were scored for each genotype, and several representative wings for each genotype were mounted on slides under coverslips in Canadian Balsam and examined under a compound microscope for detailed assessment of the wing vein pattern. Wing veins were scored as dark thickenings of the cuticle with higher bristle densities than surrounding intervein areas. These criteria permit unambiguous objective identification of vein cuticle at high magnification.

Shorthand symbols for scored phenotypes in parentheses are as follows: (L3 to margin) Longitudinal vein L3 connected to margin without a distal gap; $(\uparrow \Delta 3,4)$ increased surface area for deltas at the junction of veins L3 and L4 with the margin; $(\downarrow \Delta 3,4)$ less surface area of marginal deltas than in a wild-type background; (no $\Delta 3,4$ ) complete suppression of $\Delta 3,4$ to wild type; (longer r3,4) increased length (about twofold) of the extra vein rudiment between $\mathrm{L} 3$ and $\mathrm{L} 4$ and almost complete penetrance $\left({ }^{*}\right.$ ) of the extra vein rudiment; (L5 prox. to post. X-vein) L5 retracted beyond the posterior cross vein (a phenotype never observed for rhove in a wild-type background); (L2-L5 retracted) all longitudinal veins retracted significantly further than in $r$ ho ${ }^{\text {ve }}$ (see Fig. 3E); (L2 retracted) L2 vein retracted more than a short distance from the margin; (thick L3 and L4) distal portions of veins L3 and L4 well within wing blade thickened and often garnished with spurs; (rough eye) p[sevRas $1^{\text {Val12 }}$ has a dominant roughened eye phenotype that becomes extreme (i.e., lacking ommatidia in the center of the eye) when in combination with HS-rho constructs (these enhanced phenotypes are similar to the homozygous $\mathrm{p}\left[\operatorname{sev} R a s 1^{\text {val12}}\right]$ phenotype); (ND) not done. The above phenotypes were chosen for analysis because of their high degree of penetrance at room temperature $\left(>90 \%\right.$ of all individuals) in several wild-type backgrounds (including $y^{+}$vs. $\left.y^{-}\right)$. It should be noted, however, that other features of HS-rho alleles that are not fully penetrant (e.g., the presence of the r 3,4 extra vein spur between L3 and L4 in the $r h O^{M o d} H S$ line, which is $\sim 70 \%$ penetrant in males and $\sim 80 \%$ penetrant in females) are also modified in the same way as the more penetrant phenotypes but would be more difficult to quantify. Thus, the interactions shown here are judged by very conservative standards and even those weak interactions denoted by $0 /$ - are likely to be indications of real interactions. More than one allele of the test mutation was used for $E g f-r /+, S /+$, Gap $1 /+, d s /+$, inf $/+$ and $1(1)$ mys $/+$. We have also examined the interaction on HS-rho insertions with a large collection of wing vein mutants (M. Sturtevant and E. Bier, in prep.), and the rho ${ }^{v e}$ allele has been combined in double mutant combinations with the great majority of other wing vein mutants (Diaz-Benjumea and García-Bellido 1990a). Although these data are too extensive to adequately summarize here, there are only a few striking examples of genetic interactions between rho and other genes comparable with those described here. For example, we have found no dominant genetic interactions between rho and most venation mutants, including $b a, v s, v n, V n o, H, a b, r i, t t, d s r, d e t, c v-c, c p, s h f, f u, k n, t k, w g, e n$, $E(S)$, and $S u(S)$. We found a few mutations acting as dominant enhancers of HS-rho phenotypes, including Dl, DpNotch, px, net, and $b s$, and a few dominant suppressors such as Ser and ny (M. Sturtevant and E. Bier, in prep.). Interestingly, many of these latter mutants have also been shown to interact with Egf-r alleles, and do so in ways that are consistent with the way that rho interacts with Egf-r and these other mutations. Thus, the genetic interactions observed are confined to a relatively small set of genes, some of which contain EGF-like repeats and have been implicated in regulating cell-cell signaling events. 
Figure 3. Interactions between mutant alleles of rho and other ventrolateral genes in wing vein formation. (A) A Egf-rtop/DfEgf-r wing. (B) A $E g f-r^{E l p} / E g f-r^{E l p}$ wing. A prominent delta typically forms at the junction of L2 with the margin, and L3 and L4 frequently bifurcate near the margin. $(C) \mathrm{A}$ Egf-r ${ }^{\text {top }} /$ Egf-r ${ }^{\text {top }}$; $r$ ho $o^{\text {ve }} / r_{h} o^{\text {ve }}$ wing. A similar phenotype is observed with $\operatorname{DfEgf-r/+}$; $r h o^{v e} / r h o^{v e}$. All longitudinal veins are shortened (L2 most dramatically). L5 is drawn back behind the posterior cross vein, which never occurs in our $r o^{v e} / r h o^{\text {ve }}$ stock. $(D) \mathrm{A}$ $E g f-r^{E l p} / E g f-r^{E l p} ; \quad r h o^{v e} / r h o^{v e}$ wing. The $r h o^{v e} / r h o^{v e}$ phenotype is almost completely suppressed. L2-L4 are complete, and L5 is substantially lengthened. Heterozygous $E g f-r^{E l p}$ (which has little phenotype on its own) also suppresses $r h o^{v e} / r h o^{v e}$ to a lesser extent ( $\mathrm{L} 4$ is lengthened but not complete). (E) A Egf-r ${ }^{\text {top }} / \mathrm{DfEgf-r}$; $r \mathrm{o}^{\mathrm{ve}} / \mathrm{rho}^{\mathrm{ve}}$ wing. The loss of all L3, most of L2, and the proximal segments of L4 and L5 in this double mutant is striking, as neither Egf-r ${ }^{\text {top }} / \mathrm{Df} E g f-r$ nor $r h o^{v e} / r h o^{v e}$ alone disrupt these vein segments. (F) A Egf-r $\mathrm{r}^{E l p} /+$; rho $\mathrm{Mod}^{\mathrm{M}} \mathrm{HS} /+$ wing. The rho Mod HS extra vein phenotype is enhanced. L3 and L4 deltas are accentuated, and extra vein spurs are frequent (often posterior to L4 at the margin or posterior to L5 near the posterior cross vein). $(G)$ A $G a p 1^{E G-2} / D f G a p 1$ wing. The Gap1 ${ }^{E G-2}$ allele is the result of an insertion of the P-lacW enhancer trap vector (Bier et al. $1990)$ into the Gap1 locus. Extra vein material is typically found between L2 and the margin, and L2 is broadened. Wings of flies homozygous for the Gap $1^{B 2}$ allele described by Gaul et al. (1992) look virtually identical to $r h o^{M o d} H S /+$ wings. (H) A Gap1 $1^{E G-2} /+$; rho ${ }^{\text {Mod HS }}$ / + wing. Heterozygous Gap1 $1^{E G-2 / a}$ recessive mutation) significantly enhances the $r h o^{M o d} H S$ extra vein phenotype. Ectopic vein rudiments form in addition to exaggeration of the rho ${ }^{\text {Mod } H S}$ phenotype. $(I)$ A $S /+$; $r h o^{v e} / r h o^{v e}$ wing. Heterozygous $S$ enhances the rho ${ }^{v e} / r h o^{v e}$ loss-of-vein phenotype. L2 is greatly shortened, and L5 is drawn back behind the posterior cross vein. This enhancement is yet more severe in $S \mathrm{spi} /+$; $r \mathrm{ro}^{\mathrm{ve} /}$ $r h o^{v e}$ wings demonstrating a role for $s p i$ in vein formation. spi/ + also enhances $r h o^{v e /}$ rho ve (particularly L2) and reduces the frequency of the extra vein phenotype observed in $r h o^{\text {Mod } H S}$ flies. (J) A S/+; rho ${ }^{S t g}$ $H S /+$ wing. Heterozygous $S$ strongly suppresses the $r h O^{S t g} H S$ phenotype. Blistering is completely eliminated, broadening of veins and deltas are greatly reduced, and the extra vein rudiment between L3 and L4 is suppressed. Wings of this genotype can be difficult to distinguish from wild type. tive wing vein primordia is crucial because lack of rho expression in $r h o^{v e} / r h o^{v e}$ presumptive vein cells leads to loss of adult veins, whereas ectopic expression of rho during wing development induces the formation of extra
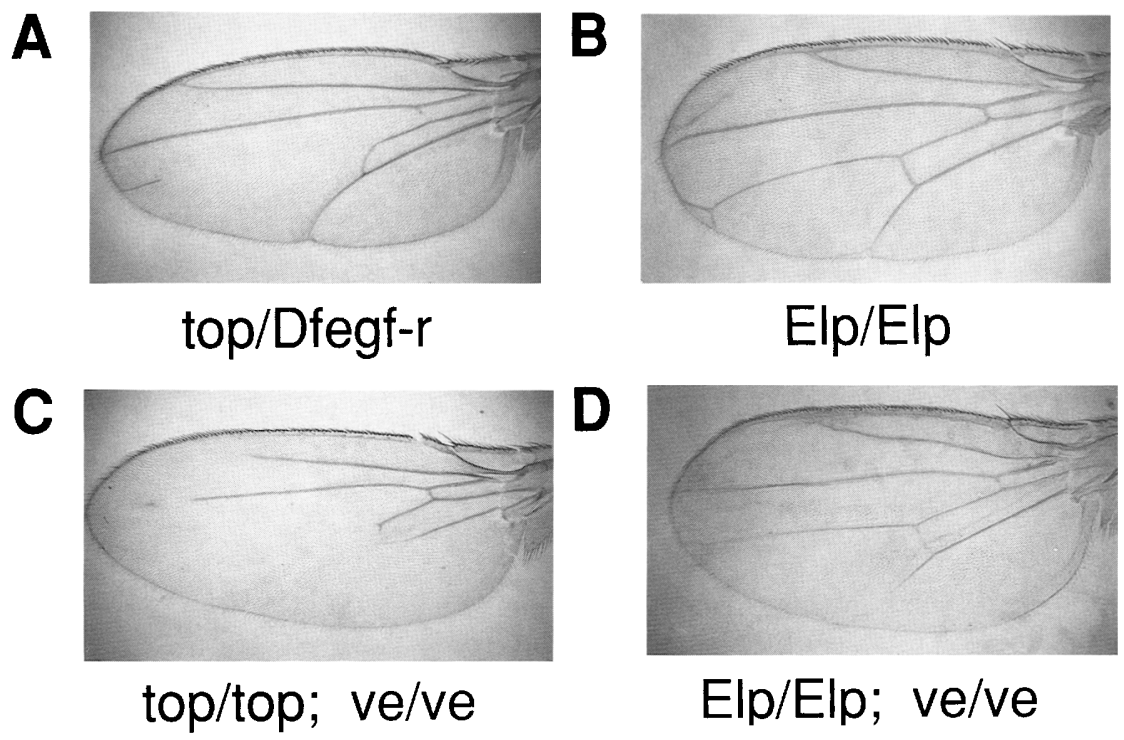

Elp/Elp; ve/ve

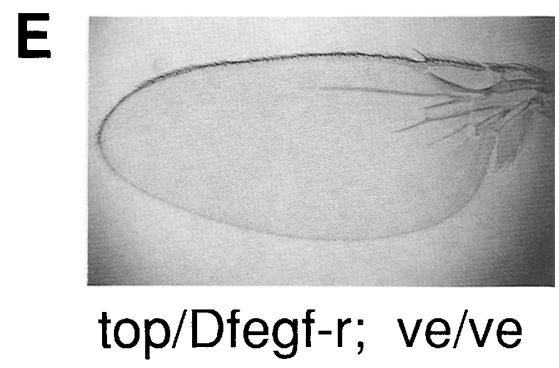

\section{1}

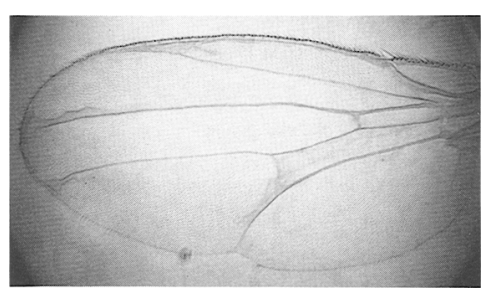

Elp/+; Mod HS/+
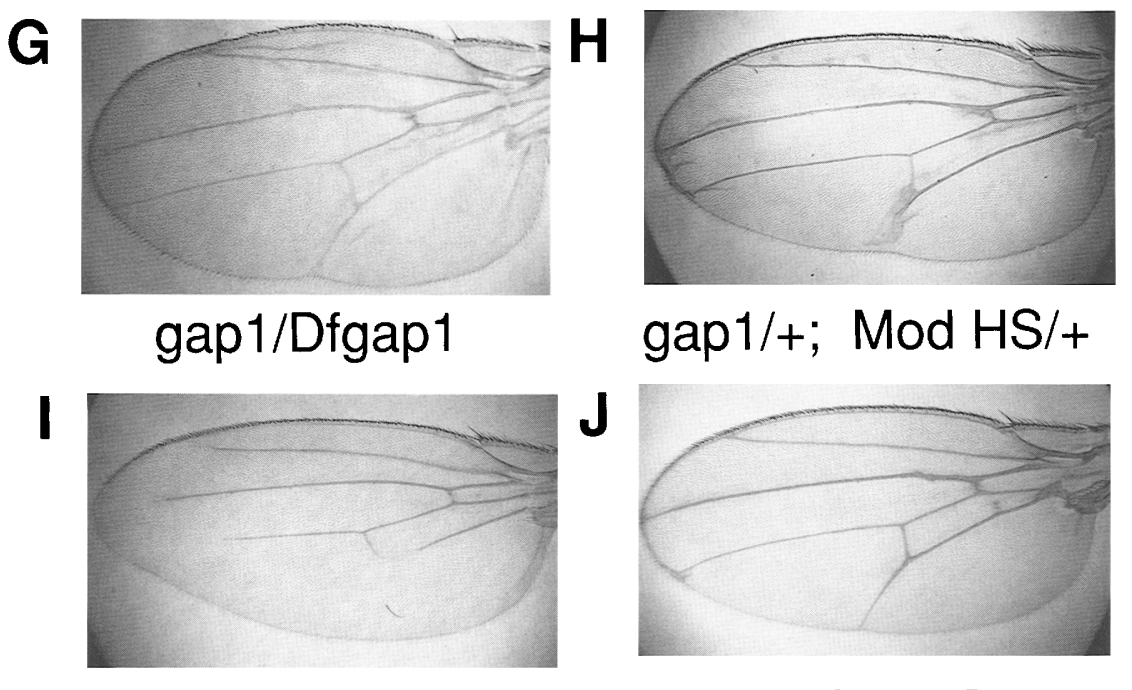

$\mathrm{S} /+; \mathrm{Stg} \mathrm{HS} /+$ veins. Dosage-sensitive interactions between rho alleles and mutations in other ventrolateral genes support models in which $r$ ho functions by hyperactivating EGF-R signaling. Because both the putative ligand $(\mathrm{Spi})$ and recep- 
tor (EGF-R) are ubiquitously expressed in wing discs, rho is likely to provide spatial specificity for restricting wing vein formation to appropriate locations.

\section{rho is expressed in wing vein primordia}

rho is the earliest known gene to be expressed in a pattern of intersecting rows of cells in wing imaginal discs likely to be the primordia of wing veins. The correspondence of rho stripes with vein primordia is supported by double-labeling experiments in which rho expression colocalizes with known wing vein markers. The rho stripes marking presumptive veins L2-L5 cross the future margin. Because the margin divides the wing disc into dorsal and ventral anlagen, vein formation is likely to be initiated independently on both surfaces of the wing. Cells at the margin also express rho in two tightly spaced rows, one on the dorsal surface and the other on the ventral surface. The expression of rho on both separated presumptive wing surfaces is consistent with genetic observations suggesting that $r h o^{v e}$ disrupts wing vein formation during the third larval instar prior to disc eversion and subsequent apposition of the dorsal and ventral surfaces (García-Bellido 1977).

When the two wing surfaces come together as the wing everts, refinement may be necessary to bring the two surfaces into strict alignment. The independent initiation of pattern in two separate regions destined to form a single structure as a result of subsequent morphogenic events is reminiscent of the formation of midline cells in the embryo from initially separate ventrolateral rows of blastoderm cells. rho expression in tracheal pits is another example of isolated groups of cells that will later join to form a unified structure. Perhaps, the rho protein is functioning in each of these cases to facilitate the mutual recognition and merging of spatially distinct groups of cells into a single coherent structure.

\section{Localized rho expression is required for wing vein formation}

rho expression along presumptive veins in wing discs is required for vein formation because rho expression is greatly reduced or missing entirely from longitudinal wing vein primordia in $r h o^{v e} / r h o^{v e}$ mutant discs and large portions of longitudinal veins are missing in $r h o^{v e /}$ $r h o^{v e}$ flies. On the other hand, rho expression along the presumptive margin is normal in $r h o^{v e} / r h o^{v e}$ discs and the margin is unaffected in $r h o^{v e} / r h o^{v e}$ flies. The loss of rho expression along longitudinal veins in $r h o^{v e} / r h o^{v e}$ discs is more severe than the loss-of-vein phenotype. This discrepancy is not likely to be the result of low but functionally important levels of rho expressed along vein primordia in $r$ hove that are not detected by in situ hybridization, because in mosaics, clones homozygous for the $r h o^{d e l 1}$ null allele only delete vein segments in portions of the wing lacking veins in $r o^{\text {ve }}$ mutants $(\mathrm{M}$. Sturtevant and E. Bier, in prep.). These data suggest that either rho is unimportant for formation of portions of veins that are intact in $r h o^{v e}$ mutants or that other spa- tial cues act in concert with rho to determine the location of vein formation. Genetic interactions (see below) favor the latter alternative, that rho establishes the vein versus intervein cell fate choice in combination with other partially redundant cues.

Ectopic rho expression during wing development is sufficient for inducing wing vein fates in many more cells than normal. Weak and moderate HS-rho phenotypes are predominantly restricted to distal portions of wing veins. Because the loss of veins in $r h o^{v e} / r h o^{v e}$ flies is restricted to distal portions of the veins, it appears that this region of the wing is most sensitive to the level of rho expression. Strong HS-rho phenotypes include thickening of wing veins and fusion of veins, which when extreme converts much of the wing surface into vein tissue, causing large blisters. As loss of rho expression leads to the truncation of wing veins while ectopic rho expression induces the formation of excess wing vein material, we conclude that rho activity is necessary and sufficient for inducing vein differentiation in many wing imaginal cells. Thus, rho functions during wing vein development as it does during embryogenesis to translate positional information established by patterning genes into coherent differentiation programs.

\section{Genetic interactions between rho and Egf-r mutations in wing development}

There are often dosage-sensitive interactions between mutations in genes functioning in a common genetic pathway. Strong dosage-sensitive interactions can indicate physical interactions between gene products or synergistic function in a particular process. We combined both loss-of-function $r h o^{v e}$ and gain-of-function $r h o^{H S}$ alleles of different constitutive strengths with mutations in other ventrolateral group genes to determine which genes rho might interact with most intimately. From these crosses we observed strong interactions between rho and $E g f-r$. Combining gain-of-function alleles of both $r h o\left(r h o^{H S}\right)$ and $E g f-r\left(E g f-r^{E I_{P}}\right)$ enhances formation of extra veins, whereas combining loss-of-function alleles of these genes $\left(r h o^{v e}\right.$ and Egf-r $\left.r^{\text {top }}\right)$ greatly exacerbates the loss of vein phenotype. In addition, combining loss-offunction $r h o^{v e}$ and gain-of-function Egf-r ${ }^{E l p}$ leads to nearly wild-type wing development. Although these double mutant combinations of partial loss-of-function alleles are consistent with a model in which rho acts upstream or in parallel with EGF-R, such an epistatic relationship cannot be established without performing mosaic analysis with stronger loss-of-function alleles.

The virtually complete suppression of the $r h o^{v e} / r h o^{v e}$ phenotype by homozygous Egf-r ${ }^{E l p}$ suggests that rho is not the only molecule providing spatial cues for vein development because rho expression in $r h o^{v e} / r h o^{\text {ve }}$ discs, which is undetectable in any longitudinal veins other than a short segment of vein L3, is not restored by $E g f-r^{E l p}$ (M. Sturtevant, unpubl.). On the other hand, the enhancement of $r h o^{v e} / r h o^{v e}$ by decreased Egf-r or $S$ dosage suggests that $r h o$ is likely to play a role in the formation of wing veins that are not deleted in $r h o^{v e} / r h o^{v e}$. 
These data suggest that rho plays a key role in the formation of all longitudinal wing veins in combination with other spacially localized cues.

We also observed strong genetic interaction between rho and $S$, as well as interaction between rho and spi. $S$ has also been observed to interact strongly with Egf-r ${ }^{\text {top }}$ in the wing (J. Price, pers. comm.). In addition, the recessive viable asteroid allele of $S$ has been shown to be a strong enhancer of the Egf-r loss-of-vein phenotype when homozygous (Diaz-Benjumea and García-Bellido 1990b). The intense genetic interaction between rho and $S$ suggests that the $\mathrm{S}$ product may directly interact with rho (see Fig. 4). Alternatively, S may be the most limiting component of the ventrolateral pathway.

All of the genetic interactions that we have observed support a model in which rho is required to permit or to amplify Spi-EGF-R signaling. Because interactions with rho as strong as these are rare, they are very likely to represent meaningful functional interactions between rho and genes of the Spi-EGF-R signaling pathway. It should be emphasized, however, that no physical evidence for a direct interaction of Spi with EGF-R has yet

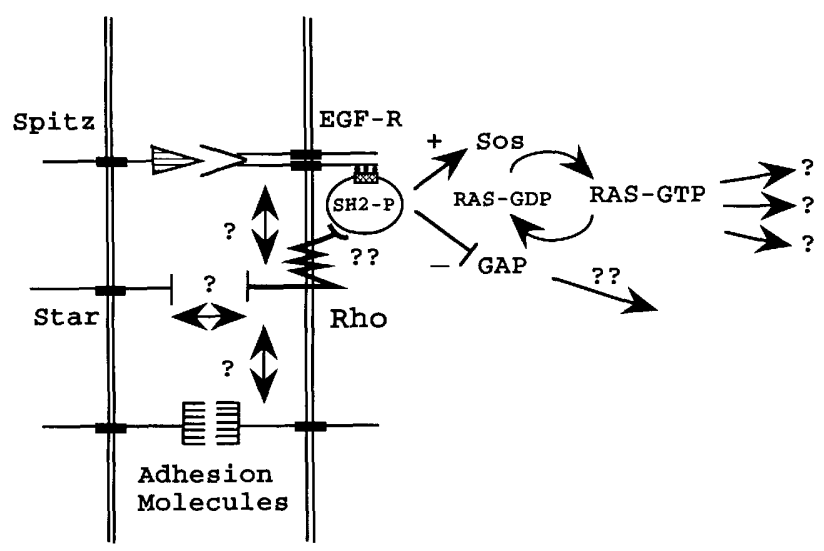

Figure 4. Mechanistic models for Rho amplification of SpiEGF-R signaling. The two main models for Rho hyperactivation of Spi-EGF-R signaling are as follows. (1) Rho functions indirectly by increasing cell-cell adhesion between communicating cells. This indiscriminately increases the likelihood of all possible receptor-ligand interactions, including Spi-EGF-R. (2) Rho acts directly to increase EGF-R activity by one of several potential mechanisms, such as increasing the affinity of EGF-R for Spi or another ligand, increasing EGF-R catalytic rate upon engaging ligand, or increasing interaction between EGF-R and downstream effectors necessary for RAS activation such as proteins containing SH2 domains. These models are not mutually exclusive. For example, Rho might bind to EGF-R and to $S$ leading to the formation of a Rho-S; Spi-EGF-R complex that would be more stable than a Spi-EGF-R complex alone. This type of model would account for the similarity in rho, S, spi, and Egf-r loss-of-function phenotypes in the embryo. It should be noted that this schematic diagram serves to illustrate the kinds of interactions that Rho may promote and undue emphasis should not be placed on any particular model. For example, the strong genetic interactions between rho and $S$ mutations may be attributable to $S$ being stochiometrically limiting rather than an indication of direct physical interaction of these molecules. been reported. Thus, signaling via other ligands and/or tyrosine kinase receptors may be enhanced by rho activity. Such potential components of the ventrolateral signaling pathway may be identified by searching for dominant suppressors of HS-rho phenotypes.

\section{Relation of the ventrolateral pathway to other developmental systems}

Signaling via the EGF-R tyrosine kinase and the sev tyrosine kinase receptor are important for different steps in the development of the compound eye (Hafen et al. 1987; Tomlinson and Ready 1987; Rubin 1991; Simon et al. 1991; Fortini et al. 1992). These studies suggest that the Sev tyrosine kinase receptor when activated by the Boss ligand (Reinke and Zipursky 1988; Hart et al. 1990; Krämer et al. 1991) activates Drosophila RAS1 (Simon et al. 1991; Fortini et al. 1992). Activated RAS is presumably in the GTP bound form as mutations in the Gap1 gene suppress a sev phenotype by leading to unregulated RAS1 activity (Fortini et al. 1992; Gaul et al. 1992). Mutations in the genes involved in RAS regulation also modify the severity of the Egf-r $r^{E l p}$ allele, suggesting that both Sev and EGF-R activate a common intracellular signaling cascade (Simon et al. 1991). RAS2 may also play a role in eye development because activated RAS2 causes a roughened eye phenotype that is distinct from that induced by activated RAS1 and does not involve sev signaling (Fortini et al. 1992).

The observations that homozygous Gap1 mutants have a wing phenotype typical of moderate rho overexpression (Fig. 3J; Gaul et al. 1992) and that $r h O^{H S}$ and rho ${ }^{v e}$ interact strongly with Egf-r, Ras1, and Gap1 alleles support the view that wing vein formation depends on the activation of RAS by EGF-R. As expression of activated RAS2 in wing discs leads to a phenotype virtually indistinguishable from that of $r$ ho ${ }^{\text {stg } H S} /+$ (A. Brand and N. Perrimon, pers. comm.), it would be interesting to test whether EGF-R signaling also involves RAS2 in wing vein formation.

A developmental pathway strongly resembling the Drosophila ventrolateral pathway has recently been described for the development of vulval cells in the nematode Caenorhabditis elegans. In vulval development a signal secreted from the anchor cell directs cell fate choices. The putative secreted signal encoded by the lin-3 gene, which like the spi gene product shares significant sequence similarity with EGF and TGF- $\alpha$ (Hill and Sternberg 1992), activates the C. elegans EGF-R encoded by let-23 (Aroian et al. 1990), which functions through a RAS protein encoded by let-60 (Han and Sternberg 1990). Thus, the EGF-R signaling pathway is not only used for several unrelated developmental decisions in Drosophila but appears to be conserved in detail throughout evolution.

\section{Localized amplification of ubiquitously distributed ligand and receptor}

Receptor tyrosine kinases have been implicated in several other important developmental decisions. For exam- 
ple, activation of the Torso receptor at the poles of the Drosophila embryo is required for formation of the terminal portions of the larva (Klinger et al. 1988), and, as mentioned above, the Sev receptor is essential for differentiation of the R7 photoreceptor in the compound eye (Tomlinson and Ready 1987). Precise spatial activation of the Torso and Sev receptor tyrosine kinases does not result from the localization of the receptor or accessory proteins but, rather, from localized ligands. In the case of the Drosophila fibroblast growth factor-receptor (FGFR), localization of the receptor may restrict signaling (Klämbt et al. 1992). The localization of a necessary or amplifying accessory molecule such as rho represents another mechanism for achieving specificity of a signaling pathway. Thus, future studies of rho may broaden the understanding of how specificity is achieved by ligand receptor systems.

\section{Potential mechanisms for hyperactivation of EGF-R signaling by Rho}

The mechanism by which the Rho protein mediates receptor hyperactivation is unknown. Several potential mechanisms for hyperactivation of EGF- $R$ by Rho are indicated schematically in Figure 4. In one class of models, Rho would function directly or indirectly to increase cell-cell adhesion (perhaps in combination with S) and thereby makes ligand (e.g., Spi)-receptor (e.g., EGF-R) interaction more likely. In an alternative but not mutaully exclusive class of models, rho would associate as a cofactor to form part of the receptor for the ligand, for example, by increasing the affinity of EGF-R for the ligand or some other required component of the signaling pathway.

Modification of specific signaling events by augmenting cell-cell adhesion is a common mechanism for regulating the extent of cell-cell signaling. This adhesionmediated process, referred to as cocapping (Singer 1992), increases the likelihood of receptor-ligand interaction by increasing the local concentration of the interacting molecules as an indirect consequence of the two cell membranes being brought into close register. The association between rho-expressing cells and clear adhesive domains is compelling. For example, during embryogenesis, rho is expressed in midline cells, tracheal pits, segment boundary cells, and cells at the dorsal edge of the epidermis during dorsal closure. The formation or function of all these structures is abnormal in $r h o^{-}$mutant embryos. During wing disc development, rho is expressed along presumptive veins; the formation of these veins is strongly dependent on adhesive interactions (Brower and Jaffee 1989; Wilcox et al. 1989; Zusman et al. 1990/. Given the strong suppression of HS-rho phenotypes by $S$ mutations, it is possible that Rho might directly mediate adhesion by binding the $S$ product. Alternatively, Rho and S could increase adhesion by modifying the activities of other adhesion molecules.

Models in which Rho interacts directly with EGF-R or other tyrosine kinase receptors to form a more active receptor for a ligand (possibly Spi) are also plausible on the basis of current data. A version of this type of model, similar in formal terms to the adhesion model, is that Rho increases the affinity of the receptor for its ligand. Although no cofactors with molecular mass or hydrophobicity profiles similar to Rho have been found to be associated with EGF-R or other tyrosine kinase receptors in biochemical studies, the nerve growth factor-receptor (NGF) provides a precedent for interactions between two low-affinity receptors creating a high-affinity receptor (Hempstead et al. 1991; Kaplan et al. 1991). Other possible mechanisms by which rho might hyperactivate EGF-R function include facilitation of receptor dimerization upon binding ligand, augmentation of receptor transphosphorylation, or facilitation of receptor association with all or a subset of primary effector molecules such as $\mathrm{SH} 2$-containing proteins.

If Rho acts to increase all functions of EGF-R equally, there must be some threshold for receptor activity above which a qualitatively different signal is elaborated. Such a threshold would explain why basal EGF-R function is required for survival of all epidermal cells during wing development and embryogenesis (Diaz-Benjumea and García-Bellido 1990b; Clifford and Schüpbach 1992; Raz and Shilo 1992), whereas hyperactivation of EGF-R signaling has specific developmental significance (DiazBenjumea and García-Bellido 1990b|. Distinct thresholds for EGF-R activity may also regulate the type of vulval cell produced in C. elegans (Sternberg and Horvitz 1986). Future biochemical studies will be required to determine whether one or more of these potential mechanisms form the basis for rho amplification of EGF-R signaling.

\section{Materials and methods}

Fly stocks

All genetic markers and chromosome balancers used are described in Lindsley and Grell (1968). Transformant HS-rho flies (kindly provided by Hannele Ruohola-Baker, University of California, San Francisco) were balanced to establish stocks. The $G a p^{E G-1}$ and $G a p^{E G-2}$ alleles were determined to be P-lacW insertion (Bier et al. 1989) in the Gap1 gene by E. Grell (University of San Francisco), B. Hay, and U. Gaul (University of California, Berkeley). The Gap1 $1^{B 2}, \operatorname{Ras}^{e 1 B}, \operatorname{sos}^{e 2 H}$, and $d r k^{e O A}$ (= Drosophila GRB2/Sem5) alleles were kindly provided by G. Rubin (University of California, Berkeley). Egf-r alleles including Egf-r $r^{\text {top-Cl}}, E g f-r^{2 L 65}$, and Egf-r $r^{D f} F 18$ were kindly provided by T. Schüpbach (Princeton University, NJ). Other stocks were obtained from the Bowling Green, Ohio and Bloomington, Indiana Drosophila Stock Centers.

\section{Heat inductions}

Late third-instar larvae or early pupae $(<10 \mathrm{hrs} \mathrm{AP} \mid$ were placed in fresh glass vials with fly food. The vials were incubated at $38^{\circ} \mathrm{C}$ for $45 \mathrm{~min}$ (in a water bath) and were then kept at $25^{\circ} \mathrm{C}$ until flies emerged.

\section{Mounting fly wings}

Wings from adult flies were dissected in isopropanol and mounted in Canadian Balsam mounting medium /Gary's Magic Mount) following the protocol of Lawrence et al. (in Roberts 1986). Mounted wings were photographed under Nomarski optics with a $4 \times$ lens on a compound microscope. 


\section{In situ hybridization to whole-mount embryos or discs}

In situ hybridization to whole-mount discs and embryos was performed using digoxigenin-labeled RNA probes (BoehringerMannheim, 1093 657), according to Tautz and Pfeiffle (1989), using $4 \mu \mathrm{g} / \mathrm{ml}$ of proteinase $\mathrm{K}$ instead of $40 \mu \mathrm{g} / \mathrm{ml}$ as required for digoxigenin-labeled DNA probes.

\section{Double labeling of discs}

Discs were fixed for $30 \mathrm{~min}$ in $0.1 \mathrm{M}$ PIPES (pH 6.9), $2 \mathrm{mM}$ $\mathrm{MgSO}_{4}, 1 \mathrm{~mm}$ EGTA, 1\% Triton X-100, and 4\% formaldehyde. After washing five times for $10 \mathrm{~min}$ each in an incubation buffer containing $50 \mathrm{~mm}$ Tris $(\mathrm{pH} 6.8), 150 \mathrm{mM} \mathrm{NaCl}$, and $0.5 \% \mathrm{NP}-40$, the tissues were then blocked for $2 \mathrm{hr}$ at $4^{\circ} \mathrm{C}$ in incubation buffer with $5 \mathrm{mg} / \mathrm{ml}$ of BSA. Subsequent incubations and washes for antibody staining were done in the incubation buffer with $1 \mathrm{mg} / \mathrm{ml}$ of BSA. For staining neuronal precursors, discs from Al01 flies (a P-lacZ reporter for neuralized) were incubated overnight at $4^{\circ} \mathrm{C}$ in $200 \mu \mathrm{l}$ of incubation buffer with a $1: 200$ dilution of rabbit-anti- $\beta$-galactosidase (Cappel). After five 10-min washes, biotinylated goat antirabbit secondary antibodies (Vector) were added at $1: 200$ for $\mathrm{l} \mathrm{hr}$ and then washed five times for $10 \mathrm{~min}$ each in PBT. At this point the antibody staining protocol was suspended and embryos were refixed in PBS with $50 \mathrm{~mm}$ EGTA and $4 \%$ formaldehyde overnight to ensure that the biotinylated secondary antibody remained in place during the subsequent whole-mount in situ protocol. The embryos were then washed and processed according to the standard whole-mount in situ protocol. Following development of the alkaline phosphatase reaction from the whole-mount in situ protocol, we resumed the antibody staining protocol at the avidin-biotinylated-HRP addition step and proceeded with the Vectastain ABC elite kit according to instructions. A more detailed description of this double-labeling method will be presented elsewhere.

\section{Construction of the HS-rho P-element vector}

As a first step in constructing the HS-rho P-element transformation vector, we trimmed a nearly full-length rho cDNA to separate the protein-coding region from $5^{\prime}$ - and $3^{\prime}$-untranslated sequences. Because the pattern of rho expression during embryogenesis is highly dynamic, it is likely that these untranslated sequences lead to mRNA instability. We particularly wished to remove $3^{\prime}$ sequences that contain 14 repeats of an RNA instability motif AUUUA. The complete Rho protein-coding open reading frame is contained on a 1060 -bp DdeI restriction fragment (Bier et al. 1990). The 5'-DdeI site lies $26 \mathrm{bp}$ upstream of the initiator ATG, and the $3^{\prime}$-DdeI site coincides with the termination codon. The ends of this DdeI restriction fragment were filled in with Klenow, and the fragment was inserted into the unique SmaI site in the Bluescript plasmid vector. A subclone was chosen having the $5^{\prime}$ end of the rho cDNA nearest the XbaI site in the Bluescript polylinker. This intermediate was linearized with EcoRI (which cuts $3^{\prime}$ to the cDNA insert), treated with Klenow, and ligated to $X b a \mathrm{I}$ linkers to create a rho-coding-region insert flanked on either side by $X b a I$ sites. The rho insert was then isolated by $X b a I$ digestion and subcloned into the $\mathrm{XbaI}$ site of the P-element heat shock vector hs-CaSpeR (Bang and Posakony 1992). We recovered both the sense (HS-rho) and antisense (HS-antirho) versions of the vector for injection into fly embryos.

\section{Other molecular techniques}

RNA probe synthesis was performed according to Boehringer-
Mannheim protocols and other cloning techniques followed standard procedures, as in Maniatis et al. (1982).

\section{Acknowledgments}

We thank Ruth Schwartz for constructing the HS-rho vector, Hannele Ruohola-Baker for injecting the HS-rho construct, Katherine Howard for assistance in mounting wings, Jason O'Neill for help with whole-mount in situ hybridization, and Michael Levine, Gary Struhl, Bill Harris, Geof Rosenfeld, Dan Lindsley, and Kathryn S. Burton for helpful discussions and critical comments on the manuscript. This work was supported by a National Institutes of Health grant (RO1-NS29870-01), an American Cancer Society (ACS) Institutional Award, and funds from the Cancer Research Coordination Committee. E.B. was supported by funds from the McKnight Neuroscience Foundation, Sloan Foundation, March of Dimes, and an ACS Junior Faculty Award.

The publication costs of this article were defrayed in part by payment of page charges. This article must therefore be hereby marked "advertisement" in accordance with 18 USC section 1734 solely to indicate this fact.

\section{References}

Aroian, R.V., M. Koga, J.E. Mendel, Y. Ohshima, and P.W. Sternberg. 1990. let-23, a gene necessary for C. elegans vulval induction, encodes a tyrosine kinase of the EGF receptor subfamily. Nature 348: 693-699.

Baker, N. and G.M. Rubin. 1989. Effect on eye development of dominant mutations in Drosophila homologue of the EGF receptor. Nature 340: 150-153.

- 1992. Ellipse mutations in the Drosophila homologue of the EGF receptor affect pattern formation, cell division and cell death in eye imaginal discs Dev. Biol. 150: 381-396.

Bang, A.G. and J.W. Posakony. 1992. The Drosophila gene Hairless encodes a novel basic protein that controls alternative cell fates in adult sensory organ development. Genes $\Leftrightarrow$ Dev. 6: 1752-1769.

Bellen, H.J., C.J. O'Kane, C. Wilson, U. Grossniklaus, R.K. Pearson, and W.J. Gehring. 1989. P-element-mediated enhancer detection: A versatile method to study development in Drosophila. Genes \& Dev. 3: 1288-1300.

Bier, E., H. Vaessin, S. Shepherd, K. Lee, K. McCall, S. Barbel, L. Ackerman, R. Carretto, T. Uemura, E. Grell, L.Y. Jan, and Y.N. Jan. 1989. Searching for pattern and mutation in the Drosophila genome with a P-lacZ vector. Genes \& Dev. 3: 1273-1287.

Bier, E., L.Y. Jan, and Y.N. Jan. 1990. rhomboid, a gene required for dorsoventral axis establishment and peripheral nervous system development in Drosophila melanogaster. Genes 4$)$ Dev. 4: 190-203.

Brower, D.L. and S.M. Jaffee. 1989. Requirement for integrins during Drosophila wing development. Nature 342: 285-287.

Campuzano, S. and J. Modolell. 1992. Patterning of the Drosophila nervous system: The acheate-scute gene complex. Trends Genet. 8: 202-208.

Carrol, S.B. and J. Whyte. 1989. The role of the hairy gene during Drosophila morphogenesis: Stripes in imaginal discs. Genes \& Dev. 3: 905-916.

Clark, S.G., M.J. Stern, and H.R. Horvitz. 1992. C. elegans cellsignaling gene sem-5 encodes a protein with $\mathrm{SH} 2$ and $\mathrm{SH} 3$ domains. Nature 356: 340-344.

Clifford, R.J. and T. Scüpbach. 1992. The torpedo (DER) receptor tyrosine kinase is required at multiple times during Droso- 
phila embryogenesis. Development 115: 853-872.

Diaz-Benjumea, F. and A. García-Bellido. 1990a. Genetic analysis of the wing vein pattern of Drosophila. Whilhelm Roux's Arch. Dev. Biol. 198: 336-354.

. 1990b. Behavior of cell mutant for an EGF receptor homologue of Drosophila in genetic mosaics. Proc. R. Soc. Lond. Biol. Sci. 242: 36-44.

Fortini, M.E., M.A. Simon, and G.M. Rubin. 1992. Signaling by the Sevenless protein tyrosine kinase is mimicked by Ras 1 activation. Nature 355: 559-561.

García-Bellido, A. 1977. Inductive mechanisms in the process of wing vein formation in Drosophila. Whilhelm Roux's Arch. Dev. Biol. 182: 93-106.

Gaul, U., G. Mardon, and G.M. Rubin. 1992. A putative Ras GTPase activating protein acts as a negative regulator of signaling by the Sevenless receptor tyrosine kinase. Cell 68: 1007-1019.

Hafen, E., K. Basler, J.E. Edstroem, and G.M. Rubin. 1987. sevenless, a cell specific homeotic gene of Drosophila, encodes a putative transmembrane receptor with tyrosine kinase domain. Science 236: 55-63.

Han, M. and P.W. Sternberg. 1990. let-60, a gene that specifies cell fates during C. elegans vulval induction, encodes a Ras protein. Cell 63: 921-931.

Hart, A., H. Kramer, D.L. Vanvactor, M. Paidhungat, and S.L. Zipursky. 1990. Induction of cell fate in the Drosophila retina-The Bride of Sevenless protein is predicted to contain a large extracellular domain and seven transmembrane segments. Genes \& Dev. 4: 1835-1847.

Hempstead, B., D. Martin-Zanca, D. Kaplan, L. Parada, and M. Chao. 1991. High affinity NGF binding requires coexpression of the trk protooncogene and the low affinity NGF receptor. Nature 350: 678-683.

Hill, R.J. and P.W. Sternberg. 1992. The gene lin-3 encodes an inductive signal for vulval development in C. elegans. $\mathrm{Na}$ ture 358: 470-476.

Jürgens, G., E. Weischaus, C. Nüsslein-Volhard, and H. Kluding. 1984. Mutations affecting the pattern of the larval cuticle in Drosophila melanogaster. II Zygotic loci on the third chromosome. Whilhelm Roux's Arch. Dev. Biol. 193: 283-295.

Kammermeyer, K.L. and S.C. Wadsworth. 1987. Expression of Drosophila epidermal growth factor homologue in mitotic cell populations. Development 100: 201-210.

Kaplan, D., B. Hempstead, D. Martin-Zanca, M. Chao, and L. Parada. 1991. The trk proto-oncogene product: A signal transducing receptor for nerve growth factor. Science 252: 554-558.

Katzen, A.L., T. Kornberg, and J.M. Bishop. 1991. Expression during Drosophila development of DER, a gene related to erbB-1 and neu: Correlations with mutant phenotypes. Dev. Biol. 145: 287-301.

Klämbt, C. 1993. The Drosophila gene pointed encodes two ETS-like proteins which are involved in the development of the midline glial cells. Development 117 163-176.

Klämbt, C., J. Jacobs, and C.S. Goodman. 1991. The midline of the Drosophila central nervous system-A model for the genetic analysis of cell fate, cell migration, and growth cone guidance. Cell 64: 801-815.

Klämbt, C., L. Gazer, and B.Z. Shilo. 1992. breathless, a Drosophila FGF receptor homolog, is essential for migration of tracheal and specific midline glial cells. Genes \& Dev. 6: $1668-1678$.

Klinger, M., M. Erdelyi, J. Szabad, and C. Nüsslein-Volhard. 1988. Function of torso in determining the terminal anlagen of the Drosophila embryo. Nature 355: 275-277.

Krämer, H., R.L. Cagan, and S.L. Zipursky. 1991. Interaction of
Bride of Sevenless membrane-bound ligand and the Sevenless tyrosine-kinase receptor. Nature 352: 207-212.

Lindsley, D.L. and E.H. Grell. 1968. Genetic variations in Drosophila melanogaster. Carnegie Inst. Washington Publ. 627.

Lindsley, D.L. and G.G. Zimm. 1992. The Genome of Drosophila melanogaster. Academic Press, San Diego, CA.

Lowenstein, E.J., R.J. Daly, A.G. Batzer, W. Li, B. Margolis, R. Lammers, A. Ullrich, E.Y. Skolnik, D. Bar-Sagi, and J. Schlessinger. 1992. The SH2 and SH3 domain-containing protein GRB2 links receptor tyrosine kinases to ras signaling. Cell 70: 431-442.

Maniatis, T., E.F. Fritsch, and J. Sambrook. 1982. Molecular cloning: A laboratory manual. Cold Spring Harbor Laboratory, Cold Spring Harbor, New York.

Mayer, U. and C. Nüsslein-Volhard. 1988. A group of genes required for pattern formation in the ventral ectoderm of the Drosophila embryo. Genes \& Dev. 2: 1496-1511.

Raz, E. and B.Z. Shilo. 1992. Dissection of the faint little ball (FLB) phenotype-Determination of the development of the Drosophila central nervous system by early interactions in the Ectoderm. Development 114: 113-123.

Reinke, R. and S.L. Zipursky. 1988. Cell-cell interaction in the Drosophila retina: The bride of sevenless gene is required in photoreceptor cell R8 for R7 cell development. Cell 55: 321330.

Roberts, D.B. 1986. Basic Drosophila care and techniques. In Drosophila: A practical approach (ed. D.B. Roberts), pp. 1-38. IRL Press, Washington, D.C.

Rogge, R.D., C.A. Karlovich, and U. Banerjee. 1991. Genetic dissection of a neurodevelopmental pathway: son of sevenless functions downstream of the sevenless and EGF receptor tyrosine kinases. Cell 64: 39-48.

Rubin, G.M. 1991. Signal transduction and the fate of the R7 photoreceptor in Drosophila. Trends Genet. 7: 372-377.

Rutledge, B., K. Zhang, E. Bier, Y.N. Jan, and N. Perrimon. 1992. The Drosophila spitz gene encodes a putative EGF-like growth factor involved in dorsal-ventral axis formation and neurogenesis. Genes \& Dev. 6: 1503-1517.

Simon, M.A., D. Bowtell, G. Dodson, T.R. Laverty, and G.M. Rubin. 1991. Ras1 and a putative guanine nucleotide exchange factor perform crucial steps in signaling by the Sevenless protein tyrosine kinase. Cell 67: 701-716.

Singer, J. 1992. Intercellular communication and cell-cell adhesion. Science 255: 1671-1677.

Sternberg, P.W. and H.R. Horvitz. 1986. Pattern formation during vulval development of C. elegans. Cell 44: 761-772.

Tautz, D. and C. Pfeiffle. 1989. A non-radioactive in situ hybridization method for the localization of specific RNAs in Drosophila reveals translational control of the segmentation gene hunchback. Chromosoma 98: 81-85.

Tomlinson, A. and D. Ready. 1987. Cell fate in the Drosophila ommatidum. Dev. Biol. 124: 264-275.

Wilcox, M., A. DiAntonio, A., and M. Leptin. 1989. The function of PS integrins during Drosophila wing morphogenesis. Development 107: 891-897.

Zak, N.B. and B.Z. Shilo. 1992. Localization of DER and the pattern of cell divisions in wild-type and Ellipse eye imaginal discs. Dev. Biol. 149: 448-456.

Zak, N.B., R.J. Wides, E.D. Scheiter, E. Raz, and B.Z. Shilo. 1990. Localization of the DER/flb protein in embryos: Implications on the faint little ball lethal phenotype. Development 109: 865-874.

Zusman, S., R.S. Patel-King, C. French-Constant, and R.O. Hynes. 1990. Requirement for integrins during Drosophila development. Development 108: 391-402. 


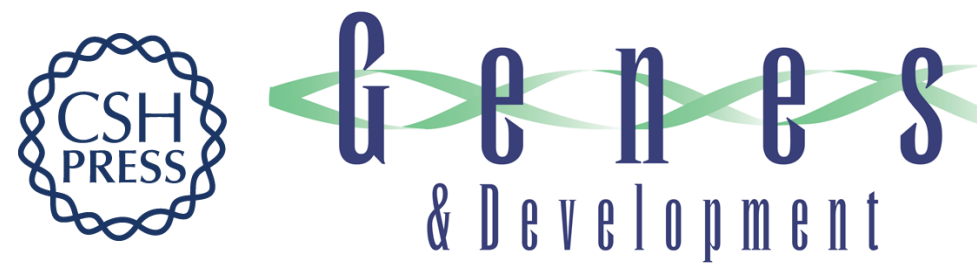

\section{The Drosophila rhomboid gene mediates the localized formation of wing veins and interacts genetically with components of the EGF-R signaling pathway.}

M A Sturtevant, M Roark and E Bier

Genes Dev. 1993, 7:

Access the most recent version at doi:10.1101/gad.7.6.961

References This article cites 47 articles, 18 of which can be accessed free at:

http://genesdev.cshlp.org/content/7/6/961.full.html\#ref-list-1

License

Email Alerting Receive free email alerts when new articles cite this article - sign up in the box at the top Service right corner of the article or click here.

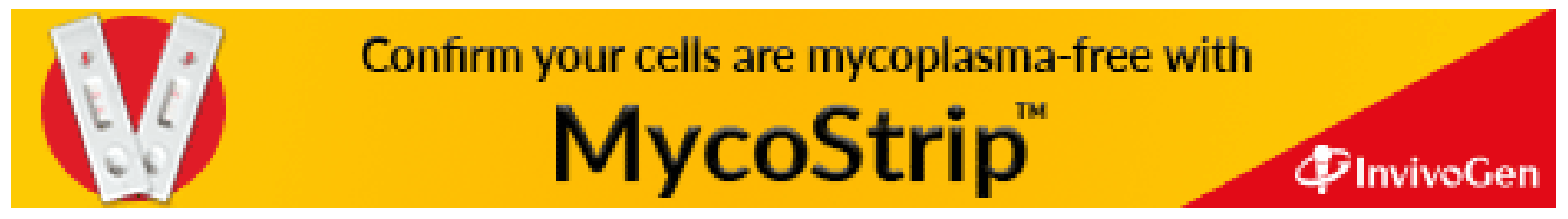

